\title{
ANDrÉs CaICEDO, A CIDADE, O CINEMA \\ ANDRÉS CAICEDO, CITY, CINEMA
}

\author{
Aline Rocha \\ Universidade Federal Fluminense \\ Niterói - Brasil
}

\section{Resumo}

Este trabalho tem como objetivo analisar as relaçóes do escritor colombiano Andrés Caicedo com a cidade de Cali no contexto sociocultural dos anos 70. Do mesmo modo, empreenderemos a leitura de textos que, ambientados no espaço urbano e na sala de cinema, figuram o encontro com a alteridade sempre no âmbito do impossível, do violento e do monstruoso.

Palavras-chave: literatura colombiana, literatura urbana, cinema, monstruoso, Andrés Caicedo.

\section{Resumen}

Este trabajo tiene como objetivo analizar las relaciones del escritor colombiano Andrés Caicedo con la ciudad de Cali en el contexto sociocultural de los años 70. Del mismo modo, emprenderemos la lectura de textos que, ambientados en el espacio urbano y en la sala de cine, figuran el encuentro con la alteridad siempre en el ámbito de lo imposible, lo violento y lo monstruoso.

Palabras claves: Literatura colombiana, literatura urbana, cine, monstruoso, Andrés Caicedo.

\begin{abstract}
This work aims to analyze Colombian writer Andrés Caicedo's links with the city of Cali in the socio-cultural context of the 1970s. Similarly, we will undertake a reading of texts that, set in the urban space and in the cinema room, present the encounter with otherness always within the scope of the impossible, the violent and the monstrous.
\end{abstract}

Keywords: Colombian literature, urban literature, cinema, monstrous, Andrés Caicedo 
Puede ser una tarde con estrellas

La tarde se parece a mi

Soy un hombre melancólico

Soy un poeta

Cuando tenía 12 años fui a mi primera fiesta y fue cuando me tocó bailar por primera vez en mi vida. Me fue muy mal.

$[\ldots]$

(trecho de um poema de Andrés Caicedo)

\section{Andrés Caicedo}

Era uma vez um escritor que olhava sua cidade pela janela poderia ser o início deste ensaio, se o tivesse escrito Andrés Caicedo. Provavelmente, se fosse de sua autoria, encontraríamos em alguma outra versão deste mesmo texto, entre seus diários e anotaçōes, um novo começo, talvez Era uma vez um cineasta que escrevia sua cidade olhando pela janela. Supondo que encontrássemos ambas as versões, não poderíamos excluir a possibilidade de numa carta haver uma terceira, ou ainda uma quarta num baú misterioso descoberto por seus amigos décadas mais tarde; e uma quinta localizada num tempo impossível e perdida pelos anos que Caicedo não viveu. Luis Andrés Caicedo Estela nasceu em 29 de setembro de 1951, na cidade de Cali, e se suicidou em 4 de março de 1977, depois de uma série de tentativas, ingerindo sessenta comprimidos de secorbabital, na mesma cidade onde nasceu e após receber o primeiro exemplar do seu ;Qué viva la música!. . Mesmo tendo se suicidado ainda muito jovem, aos vinte e cinco anos foi um criador muito ativo e plural, cujas produçóes literárias e cinematográficas, ainda pouco conhecidas no Brasil, foram traduzidas e adaptadas para diversos idiomas nas últimas décadas. A princípio conhecido e renomado como crítico de cinema, escreveu para diversos jornais colombianos, como El país, El pueblo y Occidente. Aos dezessete anos, passou a integrar o Departamento de Teatro da Universidad del Valle, onde foi diretor de vários grupos e se envolveu de múltiplas formas com o teatro, participando como diretor, ator e dramaturgo. Foi nesse mesmo período que começou a se dedicar à crítica cinematográfica e, anos mais tarde, em 1970, ingressou como ator ao Teatro Experimental de Cali (TEC).

1 Traduzida para o português (Editora Rádio Londres, 2014); francês (Belfond, 2012), inglês (Penguin, 2014) e adaptada para o cinema pelo diretor Carlos Moreno (Colômbia, 2015), ¿Qué viva la música! celebra a salsa, a juventude de Cali, e é considerado o livro mais importante de Andrés Caicedo e um dos precursores da literatura urbana colombiana. 
A paixão de Caicedo pelo cinema e sua admiração por diretores como Hitchcock, Polansky, Bergman, Buñuel, Lewis, entre outros, fez com que, em 1971, criasse - juntamente a Luis Ospina, Carlos Mayolo, Hernando Guerrero e Ramiro Arbeláez - o Cine Club de Cali, que funcionou inicialmente no Teatro Experimental de Cali, passando para a Ciudad Solar até se alocar, finalmente, no Teatro San Fernando (OSPINA, 2016) - todos esses foram espaços fundamentais para a agregação e dinâmica cultural da época. No trânsito por esses espaços e colaborando ativamente na construção de uma cena sociocultural na Cali dos anos 70, Caicedo fez de sua vida e da vida que inventou para si próprio material para suas composiçóes artísticas. De toda a correspondência que escreveu durante sua vida, guardava consigo uma cópia de cada uma das cartas que enviava a seus amigos e familiares. Nelas, não são poucas as reivindicaçóes feitas a seus amigos para que perpetuem sua obra quando não estivesse mais vivo, o que já aparece anunciado na emblemática passagem de ¡Qué viva la música!: "si dejas obra, muere tranquilo, confiando en unos pocos y buenos amigos". (CAICEDO, 2013)

É certo que a grande maioria dos seus escritos aos quais temos acesso foi organizada postumamente por seus melhores amigos e por sua família. Entre os principais, podemos destacar o volume Calicalabozo, organizado por Sandro Romero Rey e Luis Ospina, e Mi cuerpo es una celda (una autobiografía), "dirigido y montado"2 por Alberto Fuguet. Dessa passagem de ¡Qué viva la música!, um tanto premonitória e também indício de uma vida que se pensava como obra, originou-se o título do filme Unos pocos buenos amigos, documentário dirigido em 1986 por Luis Ospina - destacado cineasta colombiano - em homenagem a Caicedo, de quem fora amigo e colaborador em diversos projetos. O documentário de Ospina se inicia com a dedicatória "a mis amigos", evocando todo o contexto que vivera nos anos 70 e ressaltando a importância dos círculos afetivos nas produçóes da época. Por certo, cada uma das cenas dirigidas e montadas por ele compóe uma homenagem à amizade, à dinâmica cultural de Cali nos anos 70, aos componentes dos principais grupos artísticos da época e à juventude que participava das transformaçôes em todo o país. O filme reúne uma série de relatos e recapitula desde acontecimentos da infância de Caicedo, passando por suas conturbadas relaçóes amorosas, suas realizaçóes artísticas, e chegando finalmente aos últimos momentos de

\footnotetext{
2 Alberto Fuguet, ele próprio, irá utilizar estas palavras ao falar sobre o trabalho de compilação realizado em Mi cuerpo es una celda, no making of do livro: "Un libro, claro está, se edita, se revisa, se pule. No se dirige, no hay montaje, ni se utiliza final Cut Pro. Pero quizás éste sí se montó. No se me ocurre otra manera de entender mi proceso y mi lazo con Mi cuerpo es una celda, que el de un montajista que se encontró con mucho material y a un director-guionista que ya no está. [...] Al tener a mi lado un bolso de cuero negro con centenas de fotocopias de material inédito, entendí que quizás lo que correspondía era hacer algo cinematográfico $[\ldots]$ y no porque Andrés Caicedo fue un cinéfilo-cinépata-cinéfago de pura cepa, sino porque había algo inherentemente visual en su manera de concebir su vida y en la manera como se comunicaba con el mundo." (CAICEDO, 2008, p.295-6)
} 
sua vida e ao suicídio. Ao mesmo tempo, todas essas histórias e depoimentos de cunho biográfico se misturam e se confundem com os acontecimentos políticos e culturais de Cali, o que insere o espectador nessa conjunção entre o espaço, a produção artística e a vida de Andrés Caicedo. Sem embargo, embora a presença dos amigos fosse reiterada como elemento fundamental na composição de sua obra - a exemplo da passagem já mencionada de ¡Qué viva la música! e das diversas parcerias que estabeleceu -, os problemas dos laços afetivos em Andrés Caicedo não estão incólumes da violência que subjaz ao encontro com a alteridade. A incomunicabilidade, o abandono, a violência física e o monstruoso serão temas recorrentes em seus textos e aparecem justamente quando trata sobre a experiência urbana e as relaçóes estabelecidas na cidade de Cali.

A trajetória artística de Andrés Caicedo está fortemente marcada por todos os lugares que frequentou em sua vida, a começar por Cali, que será central em todos os seus escritos. Do mesmo modo, no que diz respeito à vida cultural, os lugares da cidade que serviram para o encontro e que trouxeram à luz o trabalho de vários artistas da época nos induzem a pensar nas práticas materiais que compóem um terreno indissociável com esta escritura.Quando formula o que seria o "regime estético das artes", Jacques Rancière (2009) ambiciona romper com os limites e modos de representação, propondo uma indiferenciação entre as categorias estéticas, éticas e políticas. Nessa perspectiva, a estética não estaria dissociada da política nem o contrário. A arte, entấo, tenderia a ser compreendida também em suas dimensóes não artísticas, ou a partir do que lhe é impróprio ${ }^{3}$. Desvinculando a estética do ideal romântico de belas artes, Rancière reabilita a noção de autonomia a partir da desidentificação que implica na construção de formas de vida e de comunidades por vir, o que coloca a arte em estreita relação com a vida coletiva. A cidade de Cali será o espaço para a performação desta coletividade na obra de Caicedo.

Feitas tais consideraçóes, o intuito deste ensaio será focalizar a relação estabelecida entre Andrés Caicedo com Cali e o modo como o cinema, em sua escritura, agencia tal relação e compóe um espaço para elaboração de formas de vida comuns que convivem em permanente conflito. $\mathrm{O}$ paradigma do monstro nos será fundamental para pensarmos esta convivência. Nesta leitura, consideraremos os aspectos históricos e sociais nos quais está inserida sua obra, bem como os procedimentos discursivos e recursos temáticos de seus textos, além de sua atuação como cineasta e realizador cultural.

3 A crítica e teórica Florencia Garramuño toma emprestado tal conceito de Roberto Esposito - filósofo que assim como Rancière reflete sobre formas de comunidade e suas impossibilidades - para se debruçar sobre práticas inespecíficas da arte contemporânea na América Latina, que transgridem "fronteras y límites disciplinarios". 
Cali es una ciudad que espera pero que no

le abre las puertas a los desesperados

(Andrés Caicedo, in.: "Infección")

Cali es un calabozo, y aqui estoy yo.

(Andrés Caicedo, janeiro de 1974, em suas anotações.)

Em 26 de fevereiro de 1971, ano marcado pela maior mobilização estudantil da história da Colômbia, o movimento organizado de estudantes da Universidad del Valle, na cidade de Cali, realizou uma manifestação em protesto à precariedade do sistema educacional, às reformas propostas pelo governo de Misael Pastrana e à influência norte-americana no país. Tal influência esteve em pleno diálogo com as reformas propostas e dizia respeito, entre outros diversos fatores comuns a toda a América Latina, à interferência financeira nos projetos sociais colombianos da entidade estadunidense Corpo de Paz, criada em 1961 pelo entáo presidente John Kennedy, que desde o final da Segunda Guerra Mundial vinha atuando com açóes voluntárias - cujos fins eram muito questionáveis e vinham de encontro à manutenção da soberania dos entâo países em desenvolvimento. Tudo isso em plena Guerra Fria e num contexto em que vários setores colombianos, influenciados pela polarização global e pelos eventos ocorridos na França em maio de 68, mobilizavamse por melhores condiçóes de trabalho. Essa manifestação, liderada pelos estudantes, foi violentamente reprimida pela polícia militar, e teve como resultado, além de diversos feridos, a morte de trabalhadores que apoiavam o movimento e de uma criança de três anos que fora pisoteada pela multidáón. O estudante Edgar Megía, que cursava Ciências da Educação, foi assassinado pelas forças do exército neste mesmo dia, durante a manifestação. Sua história e a história dos jovens daquele período influenciaram a composição do romance El Atravesado ${ }^{5}$, de Andrés Caicedo, considerado um dos melhores e mais representativos da época. No dia seguinte a essa manifestação popular, como nos lembra Alejandro Martín,

\footnotetext{
4 A leitura da tese "Estudio previo y edición crítica de la obra narrativa y dramática del escritor colombiano Andrés Caicedo", defendida em 2007 por Edwin Alberto Carvajal Córdoba pelo Departamento de Linguística General y Teoría de la Literatura da Universidad de Granada, foi de importância fundamental para a coleta dessas informaçōes e para a contextualização do período em que Andrés Caicedo viveu e produziu seus escritos.

5 A personagem principal de El Atravesado é elaborada a partir da figura de Édgar Mejía Vargas, estudante morto pela polícia militar durante uma manifestaçáo estudantil em 1971 na cidade de Cali. (ALZATE, 2000, p.140).
} 
[...] la ciudad completa amanece militarizada y el presidente Misael Pastrana decreta el Estado de Sitio en todo el país. Por supuesto, lo hace porque Cali está 'ad portas' de la inauguración de los Juegos y estas protestas estaban poniendo un manto oscuro sobre la ciudad. Así que debían reprimirlas a como diera lugar. (MARTÍN, 2017).

El Atravesado - que tem como mote central a abordagem de uma juventude que se dedica às brigas de rua, ao amor e ao cinema - foi publicado neste mesmo ano, em 1971. e embora as manifestaçóes estudantis tenham influenciado este romance, tais acontecimentos são mencionados de forma indireta e sutil. Em vez da menção explícita ao contexto político, o discurso se detém na elaboração do retrato de uma geração insatisfeita que sobrevive à violência cotidiana. Também estão ali, no decorrer da narrativa, personagens invisíveis dessa cidade, trabalhadores cuja presença se materializa nos edifícios construídos para compor os cenários dos VI Jogos Panamericanos, companheiros imóveis dos transeuntes solitários: "Y cuando vienen los días en que me siento solo, me voy para la montańa de mi aventura a ver los obreros que construyen edificios para los VI Juegos Panamericanos." (CAICEDO, 2007, p.24). A data de 26 de fevereiro de 1971 ecoa por todo o romance até que, ao final, o relato daquilo que "no se olvida", a morte do estudante, sintetiza o desfecho da narrativa:

El 26 de febrero prendimos la ciudad de la Quince para arriba, la tropa en todas partes, vi matar muchachos a bala, niñas a bolillo, a Guillermito Tejada lo mataron a culata, eso no se olvida. Que di piedra y me contestaron con metralla. Que cuando hubo que correr corrí como nadie en Cali. Que no hay caso, mi conciencia es la tranquilidad en pasta, por eso soy el que siempre tira la primera piedra. (CAICEDO, 2007, p.51)

Conta-se que Andrés Caicedo registrou esse acontecimento numa câmera caseira de $8 \mathrm{~mm}$, mas que o filme infelizmente se perdeu para sempre ${ }^{6}$. Caicedo, naquele momento, completava seus dezenove anos e era aluno do Teatro da Universidad del Valle. Mesmo não fazendo parte do movimento estudantil nem tampouco mantendo relaçóes diretas com as organizaçóes partidárias da época, seus escritos e suas produções cinematográficas foram expressivos ao tratarem da problemática dos diversos modos de violência existentes na Colômbia daquele período e, sobretudo, das relaçóes que a juventude estabelecia com a cidade e seus espaços políticos e artísticos. Sobre

6 O relato de tal episódio, feito por por Rodrigo Arbeláez, está registrado na tese de doutorado de Edwin Córdoba. Arbeláez conta o seguinte: “[...] Ese día el enfrentamiento de piedra contra fusil dejó muchos heridos y varios muertos. Andrés filmó con una cámara de $8 \mathrm{~mm}$ los sucesos del 26, pero la cinta se perdió." (p.98) 
tal característica, Alzate irá afirmar que "[...] su obra está enmarcada dentro de los fenómenos de dominación y de resistencia que se dieron en Latinoamérica como producto de un momento de crisis." (ALZATE, 2000, p. 141)

Ainda sobre o contexto colombiano deste período, pode-se dizer que a influência estadunidense não se limitou ao campo político e econômico; mas, como era de se esperar e como sucedeu com todo o Ocidente, estendeu-se para o âmbito cultural ${ }^{7}$ - desde a construçáo do imaginário de toda uma juventude até as referências musicais, literárias e cinematográficas que integravam o cotidiano e norteavam as perspectivas estéticas da geração. Nesse mesmo contexto, o cenário cultural colombiano, sobretudo aquele que se delineava na cidade de Cali, passava por um processo de efervescência e reanimação, o qual Andrés Caicedo protagonizava, e exercia um papel fundamental.

Tendo em vista o cenário sociocultural e a relevância de seus escritos no que diz respeito à formação do que se chama literatura urbana colombiana, interessa-nos pensar a partir de quais procedimentos as intersecçóes entre tais instâncias são executadas, levando em conta a dimensão comum e coletiva que as propulsionou. Ao mesmo tempo, é necessário refletir acerca do modo pelo qual o comum é tensionado à ideia que Caicedo sustenta sobre a solidáo e o encarceramento - que estáo, por sua vez, diretamente relacionados ao cinematográfico em sua obra - como condiçóes que paradoxalmente dizem respeito ao encontro, sempre impossível, com o outro: violento e monstruoso.

O cinema

Ahora acabo de salir del cine y contemplo con horror la noche que me habita dentro. (Andrés Caicedo, Diário de Nova York, 4 de outubro de 1974)

Andrés Caicedo definia a paixão e a obsessão que cultivava pelo cinema como cinesifilis, numa tentativa de associar o sentimento a uma espécie de doença que lhe tomava o corpo e colocava a relaçâo entre o conflito e a dor. Como nos lembraAlberto Fuguet:

Andrés Caicedo se consideraba más bien un cinéfago y una víctima de lo que él denominaba la cinesífilis. Organizaba cineclubes y revistas, y no hacía otra cosa que ver y ver y ver cine. Su meta era clara: tragarlo todo y, luego, escribir sobre todo lo que veía, para así, en el acto de escribir, volver a ver lo que ya había visto. (FUGUET, 2008, p.300-1)

Por certo, a escuridão das salas o impulsionava a criar, e não foram

$7 \mathrm{O}$ que ocorreu, por exemplo, no caso do Brasil com o Tropicalismo, e na Argentina com o Rock Nacional. 
poucas suas açóes e realizaçóes em torno do cinema. Em 1971, o fotógrafo e editor Hernando Guerrero ganhou uma casa de sua família, e nela começaram a se reunir jovens de toda a cidade para discutir sobre arte e política. Lá organizaram uma série de exposiçóes e ciclos de exibiçôes cinematográficas. Essa casa foi chamada de "Ciudad Solar", segundo lugar onde funcionou o Cine Club de Cali. Andrés Caicedo apoiou com veemência os eventos que aconteciam ali, inclusive financeiramente, com o dinheiro arrecadado pelo Cine Club. O manifesto do grupo, escrito por Herrero, explicita a intenção de construir novos modos de comunicaçáo tendo o cinema e a experimentação como pilares:

La Ciudad Solar es un centro aglutinante, encaminada a encontrar formas directas y efectivas de comunicación. Acumular energía, fuerzas solares que irradien y cubran extensos campos, nos aglutinamos y unificamos objetivos fundamentales y trabajamos en pos de eso. Nos abrimos a la comunicación, exploramos el campo de la imagen y el sonido en cada una de nuestras especialidades. [...] El cine como principal elemento transmisor de imágenes, de sonido. Su poder de mostrar cosas. Hacemos. Exigimos cine. Hablamos de cine. Vemos cine y publicamos cine. Se trabaja con las manos, se moldea la figura, se recrea el barro, el cuero, se buscan nuevas formas en el taller artesanal, el dibujo, el afiche, la calcomania. Son también nuevas formas de comunicación que producimos. En las artes plásticas, quienes trabajen y experimenten renovadoramente, tienen como colgar sus cuadros. Así la Ciudad Solar, es Cali, es la gran ciudad universal que busca llevar su mensaje su lucha y optismo a cada persona. (apud MARTÍNEZ, 2008, p.1)

$\mathrm{Na}$ Ciudad Solar, foi exibido pela primeira vez o filme inconcluso "Angelita y Miguel Angel", de Andrés Caicedo e Carlos Mayolo ${ }^{8}$, que não teve um desfecho por conta do desentendimento entre ambos os diretores. Durante toda a sua vida, como aquelas vontades que levamos conosco e que nos impulsionam a produzir para além de qualquer efetividade, Andrés Caicedo quis fazer um filme. Em 1974, decide partir para Los Angeles com o objetivo de apresentar e vender roteiros de longa-metragem de terror para Roger Cornan, em Hollywood. Não obteve sucesso. No entanto, como demarca Gaston A. Alzate, esta viagem teve grande relevância para a imersão de Caicedo no cinema estadunidense:

Andrés Caicedo realizó un viaje en Los Angeles en 1974 intentando vender infructuosamente un guión para un largometraje que tituló The Nameless Offspring. Fue el periodo de su vida en él que más cine vio, dejando muchas

8 Algumas cenas do filme foram recuperadas por Luiz Ospina no documentário "Unos pocos buenos amigos". 
notas y comentarios escritos en un cuaderno, que forma parte de su archivo personal que se conserva en la Biblioteca Luis Angel Arango de Bogotá. (CAICEDO, 2008, p. 62)

De fato, essa viagem fez com que Caicedo se aproximasse ainda mais do universo cinematográfico, pois frequentava todos os dias com vívido interesse e sistematização as salas de cinema de seu bairro, além de acompanhar os filmes pela televisão, como lembra em entrevista Rosario Estela Caicedo', sua irmã mais próxima que vivia nos Estados Unidos e que o manteve hospedado na época. Como o espectador apaixonado que foi, em certo momento da viagem se dedicou unicamente a ir ao cinema, como também relata:

Después vendría mi viaje a USA, a Los Angeles, para intentar vender dos guiones de horror: cuando me di cuenta de todo el problema de lenguaje que habla de por medio, desisti y me dediqué unicamente a ver cine, mientras me durara la plata. (CAICEDO, 2008, p.312).

Foi nesse mesmo período que começou a escrever ¡Qué viva la música! e a idealizar a revista $O j o$ al cine, que muito embora tenha contado com apenas cinco números foi uma das principais publicaçôes sobre o tema na Colômbia dos anos 70. Quando regressou a seu país, levou a cabo ambos os projetos:

A Colombia regresé un tanto desilusionado (Hollywood no existía) después de casi un año de pasar trabajos, de mantener un recuerdo de mi tierra magnificado por la distancia. Vine con la idea expresa de editar la revista, y a los cuatro meses ya teníamos en circulación nuestra Ojo al cine, que fue un éxito de venta y crítica. (CAICEDO, 2008, p. 312)

A paixão e o interesse de Caicedo pelo cinema se estendem para suas criaçóes literárias, repletas de referências cinematográficas fundamentais na elaboração de suas personagens e dos espaços que frequentam e ocupam, como ocorre no conto "El espectador", que narra a história de Ricardo González, jovem cinéfilo que retorna periodicamente para a mesma sala de cinema - e também para a mesma poltrona - para assistir ao mesmo filme que, podemos supor, seguindo as descriçôes da personagem, trata-se de The world in my pocket, de Alvin Rakoff, que sugere um suicídio em sua cena final. Todos os outros espectadores, companheiros anônimos que dividem com ele a sala de cinema, não compreendem a sugestâo final e detestam o filme, o que lhe causa um intenso sentimento de solidáo. Este retorno à

9 Ver entrevista de Rosario Caicedo para a Revista Arcadia: Disponível em: <http://www.revistaarcadia.com/ libros/articulo/rosario-caicedo-andres-caicedo-entrevista-segunda-parte-adolescencia-y-adultez/53906>. Acesso em 24 jul. de 2017. 
mesma sala de cinema, à mesma poltrona, ao mesmo filme, remonta-nos à repetição obsessiva comum às personagens de Caicedo, que tratam de insistir na consumação de experiências irrealizáveis, e que pelo caráter inatingível obedecem à ordem da melancolia.

Suas personagens, muitas vezes, são construídas como alter egos dele próprio, a exemplo de Ricardo, que assim como Caicedo tem o cinema como sua grande paixão. A recorrência com a qual frequentava as salas escuras é reiterada em diversas passagens do conto: "llevo tanto tiempo yendo al cine que hasta conozco el olor de las personas que se me presentan en la pantalla" (CAICEDO, 2003, p.46). Embora sua rotina fosse marcada pelo tempo que passava no cinema e sua subjetividade construída tendo como base as experiências que vivia ali, a tentativa de encontro e comunhão com o outro - nunca realizada - acontece em outro ambiente, no espaço da cidade, enquanto caminha pelas ruas imaginando uma companhia com quem pudesse compartilhar seus pensamentos.

[...] Lo mejor es cuando comparto las alegrías de la gente al salir de una gran película, o cuando pido la plata a gritos cuando la película ha sido mala. [...] Pero si yo tuviera a una persona amiga que le gustara el cine, las cosas serían mucho más fáciles. (Idem, p.47)

Além de The world in my pocket, há um outro filme que demarca um segundo conflito do conto. Trata-se de You're a big boy now, de Francis Coppola, primeiro filme oficial do diretor, cujo enredo se desdobra a partir da iniciação sentimental de Bernard, um rapaz com traços infantis que aos dezenove anos é expulso da casa paterna e desbrava a cidade de Nova York. Assim como Bernard e como Caicedo (torna-se cada vez mais difícil dizer de qual vida estamos falando), Ricardito percorre a cidade num processo de autodescoberta e autodestruição. Ao final desse filme, mais um vez, a personagem se sente desolada com a repulsa de todos, mas se surpreende quando, de súbito, ouve uma voz dissonante: "Es una gran película, lo mejor que he visto en este año" (Idem, p.48).

Daí em diante, a trama se desenvolve em torno da busca de Ricardo pelo garoto que havia feito a afirmação positiva e entusiasmada sobre o filme. A personagem sai da sala de cinema, percorre a cidade e, na esperança de encontrar este possível companheiro, elabora estratégias de aproximação. Quando o encontra de fato, a comunhão é mais uma vez adiada de forma brutal. O que Ricardo esperava ser um companheiro com quem pudesse conversar sobre filmes, acaba por ser o garoto que o espanca por tomá-lo por homossexual. Mas Ricardo continua indo ao cinema. Em "El espectador", Cali funciona como o espaço do encontro nunca realizado, cuja tentativa é 
marcada pela incomunicabilidade e pela violência.

[...] A Ricardo le gustaría decirle a cualquier persona lo bello de algunas escenas de esa película, pero se calla, sabe que tiene que callarse, y cuando sale del cine recorre esta ciudad, hablando solo y mirando al suelo, conociendo de memoria los andenes y repitiéndose colores, caricias y palabras que ha visto en la pantalla. (Idem, p.53)

A experiência estética aqui é atrelada à experiência urbana, bem como ocorre em outros escritos de Caicedo, a exemplo das historietas intituladas "Destinitos fatales". Publicado em 1971 no primeiro número da revista Ojo al cine, entre notas acerca do terror de Roman Polansky, o conto "Destinitos fatales" é dividido em três partes. Na primeira delas, um homenzinho como ele mesmo o apresenta, no diminutivo - é apaixonado por cinema e funda um cineclube (mais uma vez, aqui um alter-ego de Caicedo) cujo ciclo programado apresentava filmes de vampiros. As primeiras sessóes, que começaram cheias, esvaziam-se semana após semana, até que restem apenas quatro espectadores dos quais "uno se mudó de ciudad, otro ameneció un día muerto, uno se graduó en arquitectura y nunca nadie más lo volvió a ver por estas tierras." Quando apresentou o último filme do ciclo, com apenas uma pessoa na sala, "el hombrecito iba a comenzar a hablar de la película que amaba tanto, pero el Conde se paró de su butaca y le sonrió, y el hombrecito tuvo que bajar los ojos." (CAICEDO, 2003, p.146). A segunda parte narra a rotina de um funcionário público que viaja diariamente no mesmo ônibus sem nunca cruzar com alguém conhecido. Numa de suas viagens, dá-se conta de que aquele ônibus não para em nenhuma parte e que os passageiros lançam olhares assustadores para ele. Quando decide fazer o sinal para descer, é atacado e lhe arrancam um pedaço da bochecha. Sua maior preocupação, ao ver seu corpo mutilado, é o que dirão seus companheiros quando virem o ocorrido no noticiário do dia seguinte. "Pero mańana no va a salir nada en el periódico" (Idem), é como termina o conto, aludindo às notícias sobre atos de violência nas grandes cidades. Por fim, a terceira e última parte conta a história de um jovem "muy bondadoso y un poco ingenuo" que atravessa a cidade insolitamente levando um livro de $5 \mathrm{~kg}$ de Edgar Allan Poe e, por tão estranha figura, vira motivo de chacota. Um garoto qualquer o aborda com tom de deboche, o que o induziu a um estado de profunda tristeza durante cinco dias "hasta que se encuentra en una película una actriz americana de la que se puede enamorar fácil, y la tristeza se le pasa” (Idem, p.147). O conto, considerando a unidade de suas três partes, estabelece uma narrativa cíclica, começando e terminando com a imagem do cinema. Primeiro, pelo cineclubista, e depois pela tristeza do jovem remediada na sala de cinema. Similarmente ao que ocorre no conto "El espectador", a vivência na cidade 
complementa a experiência cinematográfica, e ambas são marcadas pelo sofrimento, pela morte e pela impossibilidade de contato com o outro.

Caicedo tem sua obra pontuada pelo gesto do suicídio, e sua vida marcada por um contexto histórico e social determinado pela violência, o que marcou tanto suas produçóes quanto o modo como se desenvolveu a recepção de seus escritos. No documentário Unos pocos buenos amigos, Oscar Ocampo relata em tom austero e grave que o primeiro indício da morte de Caicedo que sentiu logo após o seu suicídio foi a queda de três morcegos em seu quarto. Para além do quão verídico isso possa ser, o fato é que tamanha era a obsessão de Caicedo por esse tema, que sua imagem já estava impregnada de tal simbologia. Todos os componentes que orbitavam em torno do Cine Club de Cali e da Ciudad Solar tinham, nas palavras de Hernan Nicholls, "el [vampirismo] como una fijación casi infantil pero permanente", o que muito se deve, segundo Enrique Buenaventura, a "la violencia, sobretodo en esa región del Valle del Cualca, [que] dá un pie de motivo a esa facinación”. Num mesmo viés, Carlos Mayolo relembra ainda que todos daquela geração "vivimos momentos muy horrorosos de la historia pasada" ${ }^{10}$.

Já era evidente nas primeiras críticas cinematográficas de Andrés Caicedo e nas produçóes empreendidas junto a seus companheiros a importância das referências às figuras canibais, góticas e vampirescas. $\mathrm{O}$ poema a seguir, um dos poucos recuperados de Caicedo, é também exemplar no desenvolvimento dessa temática.

Creo en fantasmas, vampiros y

en empleados públicos que una

mańana salen volando de su

casa porque soy un hombre

que cayó bajo el amor.

Cuando puedo veo cine y miro

gente desde buses, merced de a

un solo sentimiento:

la nostalgia y la tristeza.

Y fijese que

digo uno.

Tengo 19 años y escribo cuentos

fantásticos.

$Y$ ya le dije que creía en vampiros.

Há, nesse poema, uma interessante justaposição dos cidadãos comuns às

10 As falas fazem parte do documentário Unos pocos buenos amigos, de Luis Ospina. 
figuras monstruosas. Funcionários públicos, vampiros e fantasmas são postos em paralelo a partir de uma voz que afirma acreditar em todos eles igualmente. Esses empregados que saltam de suas janelas colocam-se, no impulso de tal gesto, entre o ímpeto de liberdade e a morte. Vemos aqui também outra justaposição de duas imagens que podem sintetizar sua poética: o cinema e o ônibus. Nos versos "Cuando puedo veo cine y miro/ gente desde buses", Caicedo coloca o ato de assistir a vidas em telas cinematográficas e o observar as pessoas caminhando pelas ruas através das janelas do ônibus em patamar de similitude, num notável gesto de aproximação entre a arte e a vida.

Dizer "tengo 19 años y escribo cuentos fantásticos" não pode passar como um mero detalhe de cunho autobiográfico no poema. É importante lembrar que tudo isso foi escrito num momento em que Gabriel Garcia Marquez - cujo livro Cien años de soledad fora publicado em 1967 - era a maior referência literária colombiana, o que potencializa ainda mais a dimensão do deslocamento paradigmático proposto por Caicedo: uma literatura que considera o mágico e o irreal não mais no âmbito supersticioso e sobrenatural, mas sim no que há de mais terrível do dia-a-dia urbano.

Diante disso, vale nos perguntar: que cidade é essa que se olha da janela do ônibus em movimento? Que filmes são estes que os olhos miram com fulgor? O monstruoso, na obra de Caicedo, funciona como uma das facetas de uma subjetividade fragmentada, uma espécie de alteridade formulada a partir do "mesmo"11. Como propóe Joffrey Jerome Cohen em sua quarta das sete teses que elabora sobre o monstro:

O monstro é a diferença feita carne; ele mora no nosso meio. Em sua funçáo como Outro dialético ou suplemento que funciona como terceiro termo, o monstro é a incorporação do Fora, do Além - de todos aqueles loci que são retoricamente colocados como distantes e distintos, mas que se originam no Dentro. (COHEN, 2000, p. 32)

A violência da cidade figurada pelo monstruoso coloca em conjunção corpo e espaço. Essa violência urbana que demarca toda a obra de Caicedo está atrelada ao monstruoso como única possibilidade de contato com o espaço, com o outro e com o "eu".

Nesse brilhante poema de Andrés Caicedo, vampiros e fantasmas, personagens míticos e irreais, e funcionários públicos, esses seres que nos remetem às burocracias das grandes cidades, são assimilados de modo igualitário pelo olhar que a eles é dirigido. Tal equiparação percorre suas produçóes de modo enfático, como na bela passagem a seguir, de El Atravesado, que retrata a tristeza do vampiro que caminha sob a chuva:

Drácula muy solitário, muy eterno, ave nocturna de corto vuelo en estos

11 Como bem o formulara Jorge Luis Borges ao tratar sobre o duplo. 
tiempos muy difíciles. Ha caminado, la lluvia le ha quemado la cara y ya no le caben más recuerdos de la ciudad en esta noche suya sin nada de fortuna, nadie en las calles, ninguna mujer de cuello largo, blanco. Lo que más me gustaba era la actitud de las mujeres en el momento del mordisco, aceptar con lucidez su Destino Fatal. Pero Drácula ha salido y no ha encontrado a nadie, e igual de solo que hermoso ha halzado la cara y ha cantado al amor que puebla sus sueños, el que nadie sabe, idealista que es. (CAICEDO, 2007, p. 35).

Essa passagem de El atravesado nos mostra um Drácula taciturno, cujos sonhos são povoados de amor, rendido também à solidão e ao seu destino fatal - já não há experiência que separe a vida do monstro e a vida do humano. O Drácula, aqui, caminha tão solitário quanto Ricardito, de "El atravesado", que procura um amigo ao sair da sala de cinema, mas não encontra ninguém. O monstruoso, indo de encontro com a dialética do pensamento binário, expóe uma forma de vida limítrofe, e serão limítrofes também os modos de estar junto sugeridos por tal figura: vivências em comum articuladas entre o conflito e o desajuste, instalados na lógica do dissenso e na valorizaçáo da diferença. Entre a eternidade e a iminência do tornar-se, o monstro carrega, como afirma Cohen em sua sétima e última tese, um autoconhecimento e um conhecimento sobre nosso lugar:

Os monstros são nossos filhos. Eles podem ser expulsos para as mais distantes margens da geografia e do discurso, escondidos nas margens do mundo e dos proibidos recantos de nossa mente, mas eles sempre retornam. E quando eles regressam, eles trazem náo apenas um conhecimento mais pleno de nosso lugar na história e na história do conhecimento de nosso lugar, mas eles carregam um autoconhecimento, um conhecimento humano - e um discurso ainda mais sagrado na medida em que ele surge de Fora. Esses monstros nos pergutam como percebemos o mundo e nos interpelam sobre como temos representado mal aquilo que tentamos situar. Eles nos pedem para reavaliarmos nossos pressupostos culturais sobre raça, gênero, sexualidade e nossa percepção da diferença, nossa tolerância relativamente à sua expressão. Eles nos perguntam por que os criamos. (COHEN, 2000, 54-5)

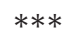

Há apenas um único registro em vídeo da voz de Andrés Caicedo - gago e tímido - gravado por Luis Ospina pouco antes do seu suicídio, recitando um poema de Cabrera Infante e falando sobre como a juventude da época preferia a música à literatura. Desfazendo a dicotomia proposta por ele próprio entre tais instâncias estéticas, podemos trazer à luz a ideia desenvolvida por Jean-Luc Nancy a respeito do modo como a literatura funciona como a voz 
que ecoa após a interrupção do mito comunitário ${ }^{12}$ - gesto a partir do qual o filósofo desloca a escritura para o âmbito da audição. Seria possível, assim, projetar no que Caicedo chama de "fórmula para a nova literatura de hoje", baseada na brevidade e na memorização executada pelo ritmo dos corpos que transitam, a propagação dessa voz " $y$ [de] su esquema [que] se imprime en el rumor de la comunidad expuesta a su propia dispersión." (NANCY, 2000, p. 76). Transcrevo abaixo as legendas do vídeo feitas por Sandro Romero y Karen Roa:

Me parece que en este momento el libro, en sí, enfrenta dos serios problemas que son, creo yo, el alto costo de los libros y el tiempo que el lector realmente ya no tiene para dedicarse y para sumirse en una lectura de 15 o 20 o 30 días. Pero ante todo la juventud se me hace que está optando es por la música, porque para oír la música no se necesita de una aceptación, sino que la puede oír en los buses, en las calles, a través de puertas abiertas, en radios prendidos. En años anteriores, se tenía el concepto de que cantidad es calidad, o sea, que un libro de 500 páginas era mejor que uno de 100 . El término además fue inventado por Cabrera Infante. A mí se me hace que la opción por la cual está tomando Cabrera Infante ahora en libros como "O", que también se puede llamar "Cero" o "Exorcismos de estilos" o "de estío", es como lo mejor. Son libros o para leer en el baño, o para leer cada 5 minutos, se puede comenzar por cualquier parte, textos muy breves, muy políticos. Yo creo que esa fórmula para la nueva literatura de hoy se puede encontrar en el poema de Cabrera Infante, personalmente uno de los mejores que he leído en 5 años, que dice, textualmente, es muy fácil de memorizar: “AAy, José!, así no se puede! ¡Ay, José, así no sé! ¡Ay, José, así no! ¡Ay, José, así! ¡Ay, José! ¡Ay!. Se me hace que un libro tan excelente como "La vorágine” puede ser ya perfectamente remplazado por las canciones de Héctor Lavoe o de Ricardo Ray \& Bobby Cruz.

Suas palavras guardam uma pretensão inaugural: a ideia de formular uma literatura possível em meio à intensidade das experiências na cidade grande que permita o entrecruzamento das instâncias estéticas e cotidianas. Nesse breve relato, o que Andrés Caicedo faz, falando também sobre Cabrera Infante, é uma síntese de seus próprios textos e dos critérios que cultivava em sua escritura, elaborada e reelaborada até a exaustão a partir de temas, frases e procedimentos repetidos obsessivamente. Como na leitura que empreende do poema de Cabrera Infante, no qual as palavras, ao mesmo tempo que se repetem, desaparecem uma a uma progressivamente; ao mesmo tempo que se estabelece o imperativo negativo, sugere-se o orgasmo - há em sua obra

12 "Existe una voz de la comunidad que se articula en la interrupción y por la interrupción misma. [...] Se le ha dado un nombre a esta voz de la interrupción: la literatura." NANCY, Jean-Luc. La comunidad inoperante. Santiago de Chile: Escuela de Filosofía Universidad ARCIS. p.76. 
uma dialética similar. Entre a negação e a afirmação, entre a permanência e o desaparecimento, na propagação de sua voz hesitante, assim funciona a literatura de Caicedo: uma poética errante inscrita num tempo de paisagens brutais.

\section{Referências bibliográficas}

ALZATE, Gastón. "El descentramiento de la palabra: Andrés Caicedo Estela". In: Literatura y cultura: Narrativa colombiana del siglo XX. Bogotá: Ministério de Cultura, 2000. p.137-160.

CAICEDO, Andrés. El atravesado. Buenos Aires: Eloísa Cartonera, 2007.

CAICEDO, Andrés. Calicalabozo. REY, Sandro Romero; OSPINA, Luiz. Bogotá: Grupo Editorial Norma, 2010.

CAICEDO, Andrés. El cuento de mi vida. Bogotá: Grupo Editorial Norma, 2007.

CAICEDO, Andrés. Mi cuerpo es una celda (una autobiografía). Dirección y montaje Alberto Fuguet. Bogotá: Alfaguara, 2008.

COHEN, Jeffrey Jerome. "A cultura dos monstros: sete teses". In: SILVA, Tomaz Tadeu da (org. e trad.). Pedagogia dos monstros: os prazeres e os perigos da confusão de fronteiras. Belo Horizonte: Autêntica, 2000.

CÓRDOBA, Edwin Alberto Carvajal. Estudio previo y edición crítica de la obra narrativa y dramática del escritor colombiano Andrés Caicedo. Tese (Doutorado em Teoría de la Literatura) - Facultad de Filosofía y Letras, Universidad de Granada. Granada, 2007.

GARRAMUÑO, Florencia. Frutos estranhos. Rio de Janeiro: Rocco, 2014.

GIRALDO, Luz Mary. "Fin del siglo XX: por un nuevo lenguaje (1960-1996)". In: Literatura y cultura: Narrativa colombiana del siglo XX. Bogotá: Ministério de Cultura, 2000. p. 9-48.

MARTÍN, Alejandro. Entrevista. In: OSPINA, Yefferson. ¿Que pasó en 1971 en Cali que cambió la historia de la ciudad para siempre? . Disponível em <http://www. elpais.com.co/entretenimiento/cultura/que-paso-en-1971-en-cali-que-cambiola-ciudad-para-siempre.html>. Acesso 24 jul. 2017.

MARTÍNEZ, Kátia Gonzalez. "La ciudad de 'unos pocos buenos amigos'”. In.: Periódico del 41 Salón Nacional de Artistas de Colombia y el 7 Festival de Performance de Cali. 2008. Disponível em <http://esferapublica.org/blancoynegro. pdf>. Acesso 24 jul. 2017. 
NANCY, Jean-Luc. La comunidad inoperante. Santiago de Chile: Escuela de Filosofía Universidad ARCIS.

OSPINA, Luis. Luis Ospina. <https://www.luisospina.com/>. Acesso 24 jul. de 2017

RANCIÈRE, Jacques. A partilha do sensivel. Trad.: Mônica da Costa Neto. 2. ed. São Paulo: EXO/Editora 34. 2009.

\section{Filmografia}

AGORA você é um homem (You're a big boy now). Direção: Francis Ford Coppola. EUA, 1967. Seven Arts Pictures. 96 minutos, sonoro, colorido. Inglês.

O MUNDO em meu bolso (The world in my pocket). Direção: Alvin Rakoff. Alemanha Ocidental/França/Itália, 1961. Central Cinema Company Films. 93 minutos, sonoro, preto e branco. Alemão.

UNOS POCOS buenos amigos. Direção: Luis Ospina. Colômbia, 1986. Instituto Colombiano de Cultura - Colcultura, Compañia de Fomento Cinematográfico. 82 minutos, colorido, sonoro. Espanhol.

Aline Rocha nasceu em 1990 na cidade de São Paulo. É escritora, professora, tradutora e doutoranda em Literatura Comparada pela Universidade Federal Fluminense com período sanduíche na Universidad de Buenos Aires. Publicou o livro de poemas Gravando (Patuá, 2013) e realiza pesquisa em Teoria Literária e Literatura LatinoAmericana Contemporânea.

E-mail: aline.rocha.oli@gmail.com 